\title{
Ion and Fluid Transport Properties of Small Airways in Cystic Fibrosis
}

\author{
Sabine Blouquit, Agathe Regnier, Luc Dannhoffer, Christophe Fermanian, Emmanuel Naline, Richard Boucher, \\ and Thierry Chinet \\ UPRES EA220, Pathology Department, and Clinical Research Unit, UFR Paris Ile de France Ouest, Université de Versailles Saint Quentin \\ en Yvelines, Boulogne, France; and Cystic Fibrosis/Pulmonary Research and Treatment Center, The University of North Carolina at Chapel Hill, \\ Chapel Hill, North Carolina
}

\begin{abstract}
Rationale: Small airways constitute a major site of pathology in cystic fibrosis (CF) and provide most of the surface area of the conducting airways of the lung. Little is known, however, about the impact of CF on ion and fluid transport in small (bronchiolar) airways.

Objectives: To describe the ion and fluid transport properties of CF bronchiolar epithelium.

Methods: Primary cultures of human bronchial and bronchiolar (non-CF and CF) epithelial cells were obtained. The bioelectric properties were studied in Ussing chambers and the airway surface liquid (ASL) height was measured with confocal microscopy.

Main Results: Primary cultures of $\triangle F 508$ CF bronchiolar epithelial cells displayed higher transepithelial resistance than non-CF cultures, whereas baseline short circuit current and amiloride-inhibitable short circuit current were similar in both preparations. The ASL height was significantly smaller in CF compared with non-CF preparations. In the presence of amiloride, addition of forskolin increased short circuit current in non-CF but not in CF bronchiolar cultures, and the ATP-induced increase in short circuit current was lower in CF than in non-CF cultures. Non-CF bronchiolar preparations displayed larger short circuit current and fluid secretion in responses to forskolin than non-CF bronchial preparations, suggesting that CFTR-dependent $\mathrm{Cl}^{-}$transport may play a more important role in the regulation of fluid transport in small airways than in large airways.

Conclusion: In CF small airways, defective $\mathrm{Cl}^{-}$secretion combined with unregulated (persistent) $\mathrm{Na}^{+}$absorption results in ASLdepletion.
\end{abstract}

Keywords: airway surface liquid; bronchiole; cystic fibrosis transmembrane conductance regulator; human; ion transport

Airway epithelial ion transport processes play a major role in the regulation of the volume and composition of the airway surface liquid (ASL) by generating osmotic gradients that provide a driving force for transepithelial fluid movement. The dominant basal ion transport in large airways is active amiloridesensitive $\mathrm{Na}^{+}$absorption that induces passive $\mathrm{Cl}^{-}$and water absorption (1). When $\mathrm{Na}^{+}$absorption is inhibited, active transepithelial $\mathrm{Cl}^{-}$secretion can be stimulated by agents that increase intracellular cAMP or $\mathrm{Ca}^{2+}$ concentrations and may reverse the direction of liquid transport toward secretion. The airway epithelium is capable of fine regulation of the ASL volume (1). The

(Received in original form June 27, 2005; accepted in final form April 27, 2006) Supported by grants from Legs Poix (Chancellerie des Universités de Paris), the Associations "Vaincre la Mucoviscidose," and the American Cystic Fibrosis Foundation.

Correspondence and requests for reprints should be addressed to Professor Thierry Chinet, Laboratoire de Biologie et Pharmacologie des Epithéliums Respiratoires (UPRES EA 220), Hôpital Ambroise Paré, 9 Avenue Charles de Gaulle, 92104 Boulogne, France, E-mail: thierry.chinet@apr.aphp.fr

This article has an online supplement, which is accessible from this issue's table of contents at www.atsjournals.org

Am J Respir Crit Care Med Vol 174. pp 299-305, 2006

Originally Published in Press as DOI: 10.1164/rccm.200506-9870C on April 27, 2006

Internet address: www.atsjournals.org crucial role of airway epithelial ion transport is illustrated by cystic fibrosis $(\mathrm{CF})$, a lethal genetic disorder that results from mutations in the cystic fibrosis transmembrane conductance regulator (CFTR) gene. CFTR exerts many functions in the airway epithelium and, in particular, acts as a cAMP-activated $\mathrm{Cl}^{-}$channel and as a regulator of other ion channels, such as the epithelial $\mathrm{Na}^{+}$channel $(\mathrm{ENaC})(2,3)$. In CF large airways, epithelial ion and fluid transport abnormalities include unregulated amiloridesensitive $\mathrm{Na}^{+}$absorption and impaired $\mathrm{Cl}^{-}$secretion $(4,5)$ that lead to ASL depletion, which promotes mucus adhesion and chronic bacterial colonization $(6,7)$.

Although small airways account for the largest portion of the total surface area of the airways and are a major site of pathology in various diseases, such as asthma, chronic bronchitis, and CF, characterization of the epithelial functions of small airways has been limited by their relative inaccessibility. Small airways share many anatomic, histologic, and physiologic features with large airways but there are also distinct regional differences. For instance, small airways do not possess submucosal glands and cartilaginous rings, and the cell populations in the mucosa are not entirely similar in large and small airways: Clara cells are absent in large airways, and basal cells, which constitute approximately $30 \%$ of the total cell number in human bronchi, are absent in bronchioles $(8,9)$.

In young children, $\mathrm{CF}$ is primarily a disease of small airways. Pathologic studies of the lungs of young children with CF reveal small airways characterized by mucus obstruction, decreased number (density), and bronchiolectasis (10-16). Examination of the bronchoalveolar lavage fluid in children with CF suggests inflammation in the distal regions of the lung $(17,18)$. Lung function studies demonstrate airway obstruction that affects distal airways more severely than proximal airways $(19,20)$. Because abnormalities in large airway epithelial ion transport are implicated in the CF lung disease, ion transport in CF small airways is also likely abnormal. We have previously reported that non-CF human bronchioles actively absorb $\mathrm{Na}^{+}$and fluid in the basal state and are capable of active $\mathrm{Cl}^{-}$and fluid secretion when exposed to agents that increase intracellular cAMP and $\mathrm{Ca}^{2+}$ concentrations (21). Here, we investigated the epithelial ion and fluid transport properties of CF small airways. We hypothesized that epithelial ion transport in CF small airways parallels that of large airways. These findings could have implications in the design of therapies aimed at correcting ion and fluid transport abnormalities in CF lung disease. Some of the results have been previously reported in the form of abstracts $(22,23)$.

\section{METHODS}

Details are provided in the online supplement.

\section{Cell Isolation and Culture}

Lung fragments were obtained from 12 non-CF patients who underwent surgery for lung cancer $(61.7 \pm 2.9 \mathrm{yr})$, from 16 healthy lung transplant donors (46.6 $\pm 4 \mathrm{yr}$ ), and from $9 \Delta \mathrm{F} 508$ homozygous patients with $\mathrm{CF}$ 
$(25.5 \pm 3.4$ yr) who underwent lung transplantation. Procedures were performed in compliance with the French legislation and the Institutional Review Board for the Protection of Human Rights at the University of North Carolina. Human non-CF and CF bronchi were identified on the basis of an outer diameter of 3 to $10 \mathrm{~mm}$ and the presence of cartilage. Non-CF bronchioles were identified by the absence of cartilage and an outer diameter $\leqslant 1 \mathrm{~mm}$. Because $\mathrm{CF}$ bronchioles exhibit bronchiectasis with increased airway diameter (13), they were selected on the basis of absence of cartilage and proximity to the pleura $(\leqslant 1 \mathrm{~cm})$. Bronchial and bronchiolar epithelial cells were isolated and cultured on collagen matrix support in air-liquid interface as previously described (21). For confocal microscopy studies, cells were cultured on Transwell-Col porous filters (Costar, New York, NY) as previously described $(24,25)$.

\section{Histologic Studies}

Preparations were embedded in paraffin and processed for standard hematoxylin and eosin staining and for immunocytochemistry.

\section{Ussing Chamber Studies}

Confluent cultures on collagen matrix support were mounted in Ussing chambers. The short-circuit current $\left(\mathrm{I}_{\mathrm{sc}}\right)$, the potential difference $(\mathrm{PD})$, and the transepithelial resistance $(\mathrm{Rt})$ were measured under baseline conditions and the effects of successive additions of amiloride, forskolin, and ATP were studied as previously described (21).

\section{Confocal Microscopy Measurement of ASL Height}

The measurement of ASL height was performed as previously described (7). The heights of ASL were measured using a laser scanning inverted confocal microscope (Leica Microsystems, Inc., Exton, PA), at baseline $(\mathrm{t} 0 \mathrm{~h})$ and at $\mathrm{t} 2 \mathrm{~h}, \mathrm{t} 6 \mathrm{~h}$, and $\mathrm{t} 24 \mathrm{~h}$ after addition of $20 \mu \mathrm{l}$ phosphatebuffered saline (PBS) containing Texas red-dextran $(2 \mathrm{mg} / \mathrm{ml})$.

To evaluate the effect of forskolin on ASL height in non-CF bronchial and bronchiolar cultures, Texas red-dextran in PBS was delivered to the apical surface of the preparations and measurements performed on the following day after stabilization of ASL height. After measurement of the initial ASL height, the cultures were exposed to amiloride (apical side), forskolin (basolateral side), or vehicles. ASL height measurements were performed before ( $\mathrm{t} 0 \mathrm{~h}$ ) and 1,2 , and $24 \mathrm{~h}$ after the addition of the drugs. To assess recovery, ASL height was also measured $24 \mathrm{~h}$ after removal of the drugs ( $\mathrm{t} 48 \mathrm{~h})$. Also studied were the effect of amiloride alone in some non-CF bronchiolar preparations at t0 $\mathrm{h}$ and $\mathrm{t} 2 \mathrm{~h}$.

\section{Statistical Analysis}

Values are expressed as mean \pm SEM. Comparisons between non-CF and $\mathrm{CF}$ data were made using the unpaired Student $t$ test. To compare the bioelectric properties of large and small airway cultures from the same patient, we used the mean of one to four bronchial cultures and one or two bronchiolar cultures for each patient, and the paired Student $t$ test. Comparison between ASL heights in bronchial and bronchiolar non-CF cultures were performed with the Proc-mixed code for repeated measurement (SAS/STAT software version 8.0; SAS, Gregy-sur-Yerres, France). A p $<0.05$ was considered as significant.

\section{RESULTS}

\section{Histologic Studies}

The cell preparations used for immunohistochemical studies were first tested in Ussing chambers to ensure that they had developed active transepithelial ion transport. Primary cultures of non-CF and CF bronchiolar epithelial cells, and of non-CF bronchial epithelial cells, were well-differentiated and exhibited typical ciliated cells (which represented the predominant cell type) and nonciliated cuboidal granular cells (Figure 1). Immunoreactivity for human cytokeratins was detected in all cells (Figure 1). Light microscopic examination revealed no significant difference between non- $\mathrm{CF}$ and $\mathrm{CF}$ bronchiolar cultures. In the comparison of non-CF cultures from different airway regions, bronchial cultures typically displayed two to three cell layers and an average height of $32.4 \pm 4.1 \mu \mathrm{m}(\mathrm{n}=5)$, whereas bronchiolar cultures usually exhibited one or two cell layers and an average height of $19.1 \pm 2.5 \mu \mathrm{m}(\mathrm{n}=6, \mathrm{p}<0.02)$.

\section{Ussing Chamber Studies of CF and Non-CF Bronchi}

The bioelectric properties of six bronchial epithelial cell cultures obtained from $\Delta \mathrm{F} 508$ homozygous patients with $\mathrm{CF}$ were measured in Ussing chambers and compared with the bioelectric properties of 18 non-CF bronchial epithelial cell cultures. The basal PD, $\mathrm{I}_{\mathrm{sc}}$, and $\mathrm{R}_{\mathrm{t}}$ of $\mathrm{CF}$ cultures were $-3.8 \pm 0.7 \mathrm{mV}, 65.4 \pm$ $15 \mu \mathrm{A} / \mathrm{cm}^{2}$, and $68.8 \pm 16.7 \Omega . \mathrm{cm}^{2}$ versus $-2 \pm 0.3 \mathrm{mV}, 29 \pm$ $4.5 \mu \mathrm{A} / \mathrm{cm}^{2}$, and $86.2 \pm 12.9 \Omega . \mathrm{cm}^{2}$ for the non-CF cultures. Changes in $\mathrm{I}_{\mathrm{sc}}$ induced by amiloride, forskolin, and ATP in CF cultures were $-53.2 \pm 14.5,-0.1 \pm 0.2$, and $25 \pm 7.1 \mu \mathrm{A} / \mathrm{cm}^{2}$, respectively (vs. $-12.9 \pm 3.3,1.6 \pm 0.4$, and $17.4 \pm 5.2 \mu \mathrm{A} / \mathrm{cm}^{2}$ ). The baseline PD, $\mathrm{I}_{\mathrm{sc}}$, and the amiloride-induced decrease in $\mathrm{I}_{\mathrm{sc}}$ were significantly higher in $\mathrm{CF}$ than in non-CF bronchial cultures $\left(\mathrm{p}<0.05\right.$ for all). In contrast, the forskolin effect on $\mathrm{I}_{\mathrm{sc}}$ in $\mathrm{CF}$ cultures was not significant and was significantly lower than in non-CF bronchial cultures $(\mathrm{p}<0.05)$.

\section{Ussing Chamber Studies of CF and Non-CF Bronchioles}

The bioelectric properties of 20 bronchiolar epithelial cultures obtained from non-CF subjects and 27 bronchiolar epithelial cell cultures obtained from $\Delta$ F508 homozygous patients with $\mathrm{CF}$ were measured in Ussing chambers. The basal bioelectric properties of the non-CF and CF cultures are shown in Table 1 . The baseline $\mathrm{PD}$ and $\mathrm{R}_{\mathrm{t}}$ were significantly higher in $\mathrm{CF}$ than in non$\mathrm{CF}$ bronchiolar cultures. In contrast, the baseline $\mathrm{I}_{\mathrm{sc}}$ was not significantly different between non-CF and $\mathrm{CF}$ preparations.

Addition of the $\mathrm{Na}^{+}$channel blocker amiloride to the apical bath significantly reduced $\mathrm{I}_{\mathrm{sc}}$ in non-CF and CF bronchiolar cultures but the amiloride-induced decrease of $\mathrm{I}_{\mathrm{sc}}$ was not significantly different in non-CF and CF preparations (Figure 2). The residual $\mathrm{I}_{\mathrm{sc}}$ in non-CF and $\mathrm{CF}$ bronchiolar cultures was different, however, $16.6 \pm 2.1$ and $10.3 \pm 1.8 \mu \mathrm{A} / \mathrm{cm}^{2}$, respectively $(\mathrm{p}<$ $0.05)$. In the presence of amiloride, exposure to forskolin significantly increased $I_{s c}$ in non-CF cultures, whereas no response was detected in CF cultures. In the presence of amiloride and forskolin, the addition of ATP further increased $\mathrm{I}_{\mathrm{sc}}$ in non-CF and $\mathrm{CF}$ bronchiolar cultures. The ATP-induced increase in $\mathrm{I}_{\mathrm{sc}}$, however, was significantly lower in $\mathrm{CF}$ than in non-CF cultures (Figure 2).

In non- $\mathrm{CF}$ bronchiolar preparations, the addition of the CFTR inhibitor DPC to the apical solution significantly decreased the $\mathrm{I}_{\mathrm{sc}}$ in the presence of amiloride $(-15.4 \pm 1.4[\mathrm{n}=8]$ vs. $-2.8 \pm 0.9 \mu \mathrm{A} / \mathrm{cm}^{2}$ for vehicle $\left.[\mathrm{n}=6] ; \mathrm{p}<0.05\right)$. The forskolin-induced increase in $\mathrm{I}_{\mathrm{sc}}$ was also significantly lower in the presence of amiloride and diphenylamine-2,2'-dicarboxylic acid (DPC) than in the presence of amiloride and the DPC vehicle $\left(0.9 \pm 0.3\right.$ vs. $\left.3.7 \pm 0.5 \mu \mathrm{A} / \mathrm{cm}^{2}, \mathrm{p}<0.05\right)$.

\section{Ussing Chamber Studies of Non-CF Bronchi and Bronchioles}

To compare the effect of forskolin in bronchial and bronchiolar epithelia, we used cell cultures obtained from the same patients to minimize interindividual variability. Eighteen cultures of bronchial epithelial cells and 12 cultures of bronchiolar epithelial cells were obtained from 10 non-CF patients (age, $61.4 \pm 3.5 \mathrm{yr}$ ). The basal bioelectric properties of these bronchial and bronchiolar cultures are shown in Table 2 . When compared with bronchial preparations, the baseline $\mathrm{PD}$ and $\mathrm{R}_{\mathrm{t}}$ of bronchiolar epithelial cell cultures were significantly lower, whereas the baseline $I_{\mathrm{sc}}$ was similar (Table 2). The amiloride-induced decreases in $I_{\mathrm{sc}}$ and the ATP-activated increases in $I_{\mathrm{sc}}$ were not significantly different in bronchial and bronchiolar preparations (Figure 3). In contrast, the forskolin-induced increases in $\mathrm{I}_{\mathrm{sc}}$ were significantly larger in bronchiolar than in bronchial cultures (Figure 3; $\mathrm{p}<0.05$ ). 

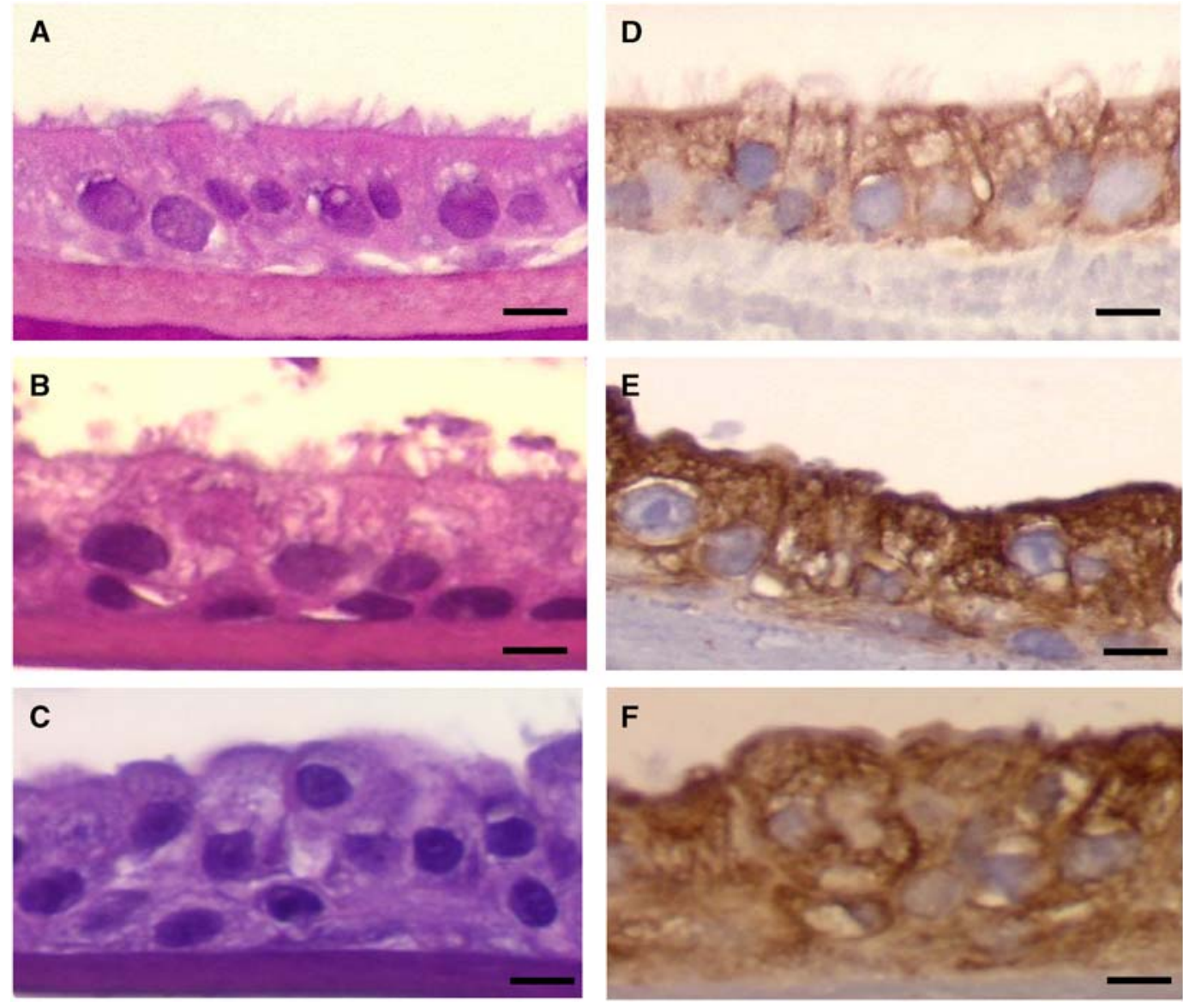

Figure 1. Histologic sections of two representative primary cultures of cystic fibrosis (CF) ( $A$ and $D)$ and non-CF ( $B$ and $E$ ) bronchiolar epithelial cells, and of non-CF bronchial epithelial cells ( $C$ and F). Three-micrometerthick sections of cultured epithelial cells were stained with hematoxylin and eosin $(A, B$, and C) (scale bars: $10 \mu \mathrm{m})$. The corresponding immunostaining with anti-CKAE1-AE3 antibodies confirmed the epithelial nature of the cultures $(D, E$, and F) (scale bars: $10 \mu \mathrm{m})$.

\section{Confocal Microscopy Measurement of ASL Height}

The effect of a volume challenge on ASL volume homeostasis was studied on bronchiolar epithelial cell cultures obtained from 11 non-CF patients (mean age, $46.1 \pm 5.0 \mathrm{yr}$ ) and from $4 \Delta \mathrm{F} 508$ homozygous patients with $\mathrm{CF}$ (mean age, $28.7 \pm 6.0 \mathrm{yr}$ ). Results are shown in Figure 4A. The initial ASL height after addition of excess periciliary liquid layer (PCL) was $26.3 \pm 1.8 \mu \mathrm{m}$ in non$\mathrm{CF}$ preparations $(\mathrm{n}=22)$ and $28.3 \pm 2 \mu \mathrm{m}$ in $\mathrm{CF}$ preparations ( $\mathrm{n}=11$, not significant). Both culture types displayed a rapid absorption of ASL during the first $12 \mathrm{~h}$, but the ASL height decreased more rapidly in $\mathrm{CF}$ than in non-CF preparations (CF: t2 h: $5.7 \pm 1.3 \mu \mathrm{m}, \mathrm{t} 6 \mathrm{~h}: 3.5 \pm 0.5 \mu \mathrm{m}$ vs. non-CF: $\mathrm{t} 2 \mathrm{~h}: 12.1 \pm$ $1.4 \mu \mathrm{m}$, t6 h: $8.1 \pm 1.2 \mu \mathrm{m} ; \mathrm{p}<0.05)$. Between t6 $\mathrm{h}$ and $\mathrm{t} 24 \mathrm{~h}$, the ASL heights were stable in both preparations and significantly smaller in CF (t24 h: $3.7 \pm 0.4 \mu \mathrm{m}$ for CF vs. $8 \pm 0.9 \mu \mathrm{m}$ for non-CF; $\mathrm{p}<0.05)$.

TABLE 1. BIOELECTRIC PROPERTIES OF CULTURED HUMAN NON-CYSTIC FIBROSIS AND CYSTIC FIBROSIS BRONCHIOLAR EPITHELIAL CELLS

\begin{tabular}{llll}
\hline & $\mathrm{PD}(\mathrm{mV})$ & $\mathrm{I}_{\mathrm{sc}}\left(\mu \mathrm{A} / \mathrm{cm}^{2}\right)$ & $\mathrm{R}_{\mathrm{t}}\left(\Omega . \mathrm{cm}^{2}\right)$ \\
\hline Non-CF bronchiolar cultures $(\mathrm{n}=20)$ & $-1.1 \pm 0.2$ & $34.2 \pm 6.1$ & $36.4 \pm 3.6$ \\
CF bronchiolar cultures $(\mathrm{n}=27)$ & $-2.1 \pm 0.3^{*}$ & $29.0 \pm 3.6$ & $84.3 \pm 8.5^{*}$
\end{tabular}

Definition of abbreviations: $\mathrm{CF}=$ cystic fibrosis; $\mathrm{PD}=$ potential difference.

The transepithelial PD, the equivalent short circuit current $\left(\mathrm{I}_{\mathrm{sc}}\right)$, and the transepithelial resistance $\left(R_{t}\right)$ were measured.

* Statistically significant difference between non-CF and CF bronchiolar preparations $(p<0.05)$
To study the effect of forskolin on ASL height in non-CF bronchial and bronchiolar preparations, cultures were obtained from lungs resected from seven patients (mean age, $51.4 \pm$ $6.9 \mathrm{yr}$ ). In control experiments, there was no significant change in ASL height measured at $\mathrm{t} 0 \mathrm{~h}, \mathrm{t} 1 \mathrm{~h}, \mathrm{t} 2 \mathrm{~h}$, and $\mathrm{t} 24 \mathrm{~h}$ in non-CF bronchial (t0 h: $7.1 \pm 0.3 \mu \mathrm{m}, \mathrm{t} 1 \mathrm{~h}: 7.2 \pm 0.4 \mu \mathrm{m}, \mathrm{t} 2 \mathrm{~h}: 7.6 \pm$ $0.5 \mu \mathrm{m}$ and $\mathrm{t} 24 \mathrm{~h}: 7.8 \pm 0.4 \mu \mathrm{m} ; \mathrm{n}=10)$ and bronchiolar (t0 h: $6.4 \pm 0.5 \mu \mathrm{m}, \mathrm{t} 1 \mathrm{~h}: 6.7 \pm 0.6 \mu \mathrm{m}, \mathrm{t} 2 \mathrm{~h}: 6.4 \pm 0.6 \mu \mathrm{m}$ and t24 h: $7.1 \pm 0.4 \mu \mathrm{m} ; \mathrm{n}=11$ ) cultures, suggesting that repeated measurements had no impact on ASL height. The ASL heights

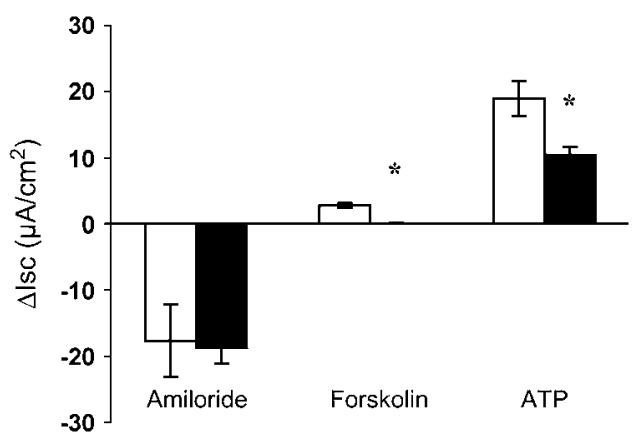

Figure 2. Changes in $I_{s c}$ induced by sequential addition of amiloride, forskolin, and ATP in primary cultures of non-CF (white bars, $\mathrm{n}=20$ preparations from 16 patients) and CF (black bars, $\mathrm{n}=27$ preparations from four patients) bronchiolar epithelial cells. *Statistically significant difference $(p<0.05)$. 
TABLE 2. BIOELECTRIC PROPERTIES OF CULTURED HUMAN BRONCHIAL AND BRONCHIOLAR EPITHELIAL CELLS FROM THE SAME PATIENTS

\begin{tabular}{|c|c|c|c|c|c|c|}
\hline & \multicolumn{3}{|c|}{ Baseline } & \multirow{2}{*}{$\begin{array}{c}\text { Amiloride } \\
\Delta \mathrm{I}_{\mathrm{sc}}\left(\mu A / \mathrm{cm}^{2}\right)\end{array}$} & \multirow{2}{*}{$\begin{array}{c}\text { Forskolin } \\
\Delta \mathrm{I}_{\mathrm{sc}}\left(\mu A / \mathrm{cm}^{2}\right)\end{array}$} & \multirow{2}{*}{$\begin{array}{c}\text { ATP } \\
\Delta \mathrm{I}_{\mathrm{sc}}\left(\mu A / \mathrm{cm}^{2}\right)\end{array}$} \\
\hline & $\mathrm{PD}(m V)$ & $\mathrm{I}_{\mathrm{sc}}\left(\mu A / \mathrm{cm}^{2}\right)$ & $\mathrm{R}_{\mathrm{t}}\left(\Omega . \mathrm{cm}^{2}\right)$ & & & \\
\hline Bronchial cultures $(n=18)$ & $-2.0 \pm 0.3$ & $29.0 \pm 4.5$ & $86.2 \pm 12.9$ & $-12.9 \pm 3.3$ & $1.6 \pm 0.4$ & $17.4 \pm 5.2$ \\
\hline Bronchiolar cultures $(n=12)$ & $-1.0 \pm 0.2^{*}$ & $32.1 \pm 4.3$ & $32.3 \pm 4.2^{*}$ & $-15.1 \pm 4.2$ & $4.4 \pm 0.9^{*}$ & $22.9 \pm 3.1$ \\
\hline
\end{tabular}

For definition of abbreviations, see Table 1.

Primary cultures of human bronchial and bronchiolar epithelial cells were obtained from 10 non-CF patients and studied in Ussing-type chambers. The transepithelial PD, the equivalent short circuit current $\left(I_{s c}\right)$, and the transepithelial resistance $\left(R_{t}\right)$ were measured. Amiloride, forskolin, and ATP were added sequentially.

* Statistically significant difference between bronchial and bronchiolar preparations $(p<0.05)$.

measured before ( $\mathrm{t} 0 \mathrm{~h})$ and after ( $\mathrm{t} 1 \mathrm{~h}, \mathrm{t} 2 \mathrm{~h}$, and $\mathrm{t} 24 \mathrm{~h})$ addition of forskolin and amiloride in bronchial and bronchiolar preparations are displayed in Figure 4B. In the presence of amiloride, the response to forskolin was significantly greater in bronchioles than in bronchi $(\mathrm{p}<0.05)$. At $\mathrm{t} 2 \mathrm{~h}$, the ASL height had increased by approximately $4 \mu \mathrm{m}$ in bronchial cultures, and by approximately $6 \mu \mathrm{m}$ on bronchiolar cultures when compared with t $0 \mathrm{~h}$, corresponding to a calculated fluid secretion of approximately 0.4 and $0.6 \mu \mathrm{l} / \mathrm{cm}^{2}$ on bronchial and bronchiolar cultures, respectively. At $\mathrm{t} 48 \mathrm{~h}$, the ASL heights in bronchial and bronchiolar cultures were not different from their values at t0 $\mathrm{h}(5.4 \pm 0.2$ and $5.8 \pm 1.8 \mu \mathrm{m}$, respectively).

To evaluate the effect of amiloride alone on ASL homeostasis, the ASL height was measured in the presence of amiloride, amiloride plus forskolin, or vehicle in non-CF bronchiolar preparations. The results are displayed in Figure 5. At $0 \mathrm{~h}$, the ASL height was $6.3 \pm 0.5 \mu \mathrm{m}(\mathrm{n}=9)$ in the amiloride group; $6.2 \pm$ $0.3 \mu \mathrm{m}$ in the amiloride plus forskolin group ( $\mathrm{n}=17)$; and $6.4 \pm 0.5 \mu \mathrm{m}(\mathrm{n}=11)$ in the vehicle group (NS). At $\mathrm{t} 2 \mathrm{~h}$, the ASL height was $8.6 \pm 0.7 \mu \mathrm{m}$ in the amiloride group; $12.9 \pm$ $1.5 \mu \mathrm{m}$ for the amiloride plus forskolin group $(\mathrm{p}<0.05$ compared with amiloride alone); and $6.4 \pm 0.6 \mu \mathrm{m}$ in the vehicle group ( $\mathrm{p}<0.05$ compared with amiloride alone and with amiloride plus forskolin).

\section{DISCUSSION}

The main objective of this study was to compare the ion and fluid transport properties of primary cultures of human non$\mathrm{CF}$ and homozygous $\Delta \mathrm{F} 508 \mathrm{CF}$ bronchiolar epithelial cells. We obtained primary cultures of bronchial and bronchiolar epithelial cells using standard procedures $(21,26)$. Histologic sections of

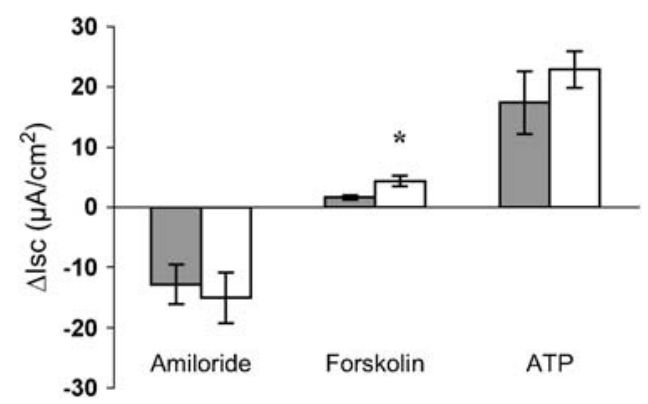

Figure 3. Changes in $\mathrm{I}_{\mathrm{sc}}$ induced by sequential addition of amiloride, forskolin, and ATP in primary cultures of non-CF bronchial (gray bars, $\mathrm{n}=18$ cultures) and non-CF bronchiolar epithelial cells (white bars, $\mathrm{n}=12$ ) from the same 10 patients. *Statistically significant difference $(p<0.05)$.
non-CF and $\mathrm{CF}$ bronchiolar epithelial cultures revealed that both were well differentiated and exhibited many of the features of small airway epithelium in vivo, including a predominance of ciliated cells. In addition, we observed no morphologic differences between $\mathrm{CF}$ and non-CF preparations. These findings are consistent with previous studies on primary cultures of non-CF and CF human epithelial cells from large airways (27). Non-CF and $\mathrm{CF}$ airway epithelial preparations were submitted to the
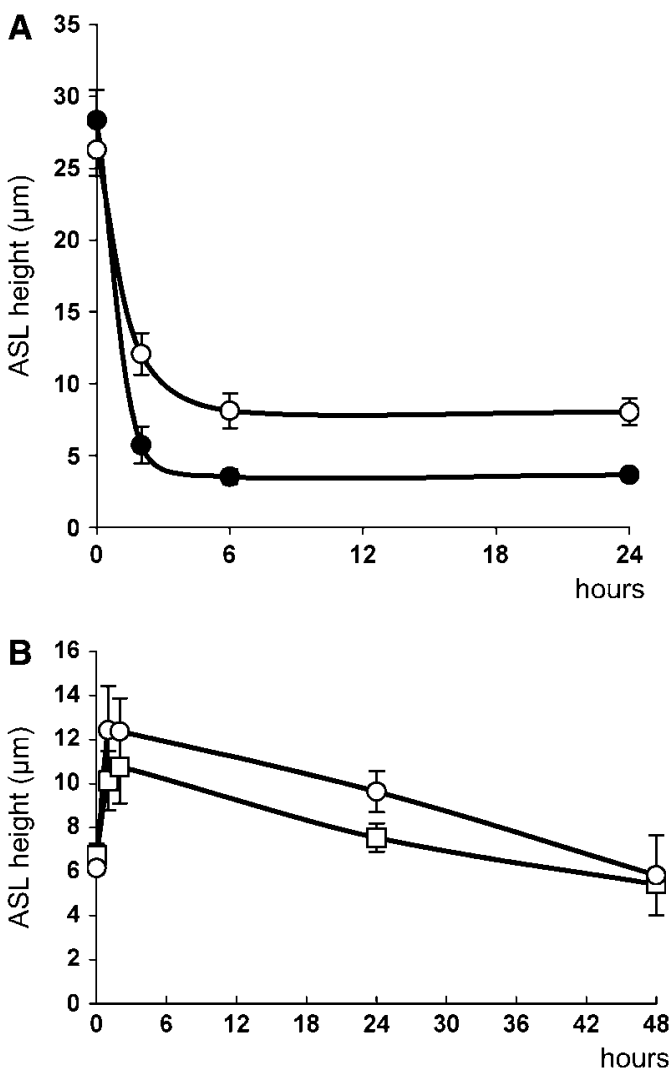

Figure 4. $(A)$ Change in airway surface liquid (ASL) height in non-CF bronchiolar (white circles, $\mathrm{n}=22$ preparations from eight patients) and in CF bronchiolar (black circles, $\mathrm{n}=11$ preparations from four patients) epithelial cell cultures exposed to an excess of liquid on the apical side. Measurements were performed at t0 h, t2 h, t6 h, and t $24 \mathrm{~h}$. (B) Change in ASL height in non-CF bronchial (white squares, $\mathrm{n}=14$ preparations) and bronchiolar (white circles, $\mathrm{n}=17$ preparations) cultures obtained from the same eight patients and exposed to forskolin in the presence of amiloride. Measurements were performed at t0 h, t1 h, t2 h, and $\mathrm{t} 24 \mathrm{~h}$. At $\mathrm{t} 24 \mathrm{~h}$, the drugs were removed and an additional measurement was performed at $\mathrm{t} 48 \mathrm{~h}$. 


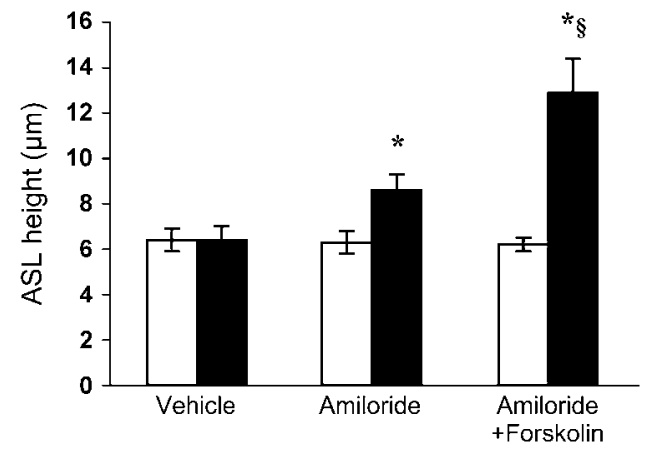

Figure 5. Measurements of the height of the ASL in non-CF bronchiolar cultures exposed during $2 \mathrm{~h}$ to amiloride alone and to amiloride + forskolin. ASL height measurements were performed at t0 $\mathrm{h}$ (white bars) and after $2 \mathrm{~h}$ (black bars) of exposure to vehicle $(\mathrm{n}=11)$, amiloride $(n=9)$, and amiloride + forskolin $(n=17) .{ }^{*} p<0.05$ compared with the vehicle group; ${ }^{\S} \mathrm{p}<0.05$ compared with the amiloride group.

same cell culture procedures, except that during the first $48 \mathrm{~h}$ after seeding ceftazidime and tobramycin were present in the culture medium of CF preparations. This addition is unlikely to have affected our results because the bioelectric measurements were performed 4 to $12 \mathrm{~d}$ after seeding. In addition, Randell and coworkers have demonstrated that ceftazidime and tobramycin do not affect the electrophysiologic properties of non-CF and CF airway epithelial primary cultures (28). We also compared non-CF bronchial and bronchiolar cultures histology and found that the only apparent difference was the thickness of the primary cultures, which mimics the in vivo situation (29).

We previously demonstrated that normal human bronchioles actively absorb $\mathrm{Na}^{+}$and fluid in unstimulated conditions and are capable of active $\mathrm{Cl}^{-}$and fluid secretion when exposed to forskolin and ATP in the presence of amiloride (21). In the present study, we compared the bioelectric properties of non$\mathrm{CF}$ and $\mathrm{CF}$ bronchiolar epithelial cells in primary culture. In the basal state, the PD was twofold higher in $\mathrm{CF}$ than non-CF bronchiolar preparations. This increase in $\mathrm{PD}$ resulted from an increase in $\mathrm{R}_{\mathrm{t}}$ in $\mathrm{CF}$ compared with non-CF cultures. An increase in transcellular electrical resistance could account at least in part for the increased $R_{t}$ because we observed a defective forskolinand ATP-stimulated $\mathrm{Cl}^{-}$secretion with no indication of a higher $\mathrm{Na}^{+}$absorption in CF compared with non-CF preparations. Increased paracellular resistance could also account for the increased $\mathrm{R}_{\mathrm{t}}$. Willumsen and coworkers (30) calculated the paracellular resistance in primary cultures of human nasal epithelial non- $\mathrm{CF}$ and $\mathrm{CF}$ cells and found that it was slightly higher in $\mathrm{CF}$ than in non-CF epithelia. A higher paracellular resistance in the bronchiolar CF preparations cannot be ruled out even though there was no histologic difference between non-CF and CF preparations on microscopic examination, in particular the number of cell layers and the height of the epithelium.

Human airway epithelial cells express ENaC and pumps $(\mathrm{Na} /$ K-ATPase) to mediate transcellular $\mathrm{Na}^{+}$absorption (5). Numerous Ussing chamber studies and the present data have demonstrated that CF nasal and large airway epithelia exhibit a twofold to threefold increase in baseline $\mathrm{I}_{\mathrm{sc}}$ and that this increase can be attributed to an accelerated amiloride-sensitive $\mathrm{Na}^{+}$absorption through $\mathrm{ENaC}$ channels located in the apical membrane of the epithelial cells $(5,27,31-33)$. We found no indication, however, of an accelerated rate of $\mathrm{Na}^{+}$absorption in $\mathrm{CF}$ bronchiolar preparations. This result was unexpected, because non-CF small airways displayed $\mathrm{Na}^{+}$transport capacities similar to those ob- served in non-CF bronchi (i.e., non-CF small airways exhibit amiloride-sensitive $\mathrm{Na}^{+}$absorption, which accounts for approximately $50 \%$ of the baseline $\mathrm{I}_{\mathrm{sc}}$ in Ussing chamber studies) (21).

Our experiments in non-CF bronchial and bronchiolar preparations from the same patients confirmed that the effect of amiloride on the baseline $\mathrm{I}_{\mathrm{sc}}$ was similar for both culture types and consistent with previous reports in excised human non-CF bronchi and cultured human bronchial epithelial cells $(34,35)$. Animal studies have also reported similar effects of amiloride on $\mathrm{I}_{\mathrm{sc}}$ in bronchial and bronchiolar preparations $(36,37)$. There seems to be a discrepancy in the magnitude of amiloride-sensitive $\mathrm{Na}^{+}$ transport between bronchi and bronchioles in $\mathrm{CF}$ tissues. $\mathrm{ENaC}$ and CFTR are expressed in both bronchial and bronchiolar epithelial cells $(38,39)$. It is conceivable that the transporters involved in the transepithelial absorption of $\mathrm{Na}^{+}$and particularly $\mathrm{ENaC}$ may not be regulated in the same way by CFTR in small and large airways. Indeed, the effect of CFTR on ENaC differs in various epithelia: CFTR downregulates ENaC activity in human large airways (5) and colon (40); in contrast, activation of CFTR $\mathrm{Cl}^{-}$channel is accompanied by a concomitant activation of $\mathrm{ENaC}$ in human sweat duct (41). This indicates that CFTR$\mathrm{ENaC}$ interactions are tissue specific and may be different in large and small airways.

Our results obtained in vitro on cell cultures may be different, however, from the in vivo situation. Indeed, our experimental conditions (i.e., Ussing chambers) expose the epithelial surface to a large volume of liquid and obviously do not represent the actual in vivo situations (i.e., it assesses the capacities of the epithelial layer to secrete and absorb ions). Recently, Tarran and coworkers demonstrated that, under conditions that are closer to the in vivo situation (primary cell cultures exposed to air on their mucosal surface during measurements), normal bronchial epithelia coordinate active absorptive and secretory ion flows to control finely the quantity of salt on airway surfaces and, hence, the ASL volume (42): when the ASL volume approaches an optimal depth (approximately $7 \mu \mathrm{m}$ ), $\mathrm{Na}^{+}$absorption is inhibited and the dominant ion transport turns to CFTRdependent $\mathrm{Cl}^{-}$secretion. In $\mathrm{CF}$ bronchial preparations, Tarran and coworkers (42) observed that $\mathrm{Na}^{+}$absorption is not inhibited (i.e., unregulated) because of the absence of the tonic inhibitory influence of CFTR on the epithelial $\mathrm{Na}^{+}$channel. This defect, plus the absence of CFTR-dependent $\mathrm{Cl}^{-}$secretion, results in a reduced ASL volume in CF. Although we did not measure the amiloride-sensitive PD after ASL volume challenges in CF bronchiolar cultures, the abnormally low volume in CF suggests that $\mathrm{Na}^{+}$transport was not normally regulated (i.e., inhibited) by low ASL volume in CF bronchioles. These data lead us to speculate that failure to regulate $\mathrm{Na}^{+}$transport with volume, perhaps more than accelerated $\mathrm{Na}^{+}$transport, is a key defect in CF pathogenesis.

In addition to $\mathrm{Na}^{+}$absorption, the epithelial cells in large airways also have the capacity to secrete $\mathrm{Cl}^{-}$when $\mathrm{ENaC}$ is blocked and the appropriate $\mathrm{Cl}^{-}$secretory driving forces are generated (5). $\mathrm{Cl}^{-}$secretion can be stimulated by agents that increase the intracellular concentration of cAMP, presumably through activation of CFTR, and by agents that increase the intracellular activity of $\mathrm{Ca}^{2+}$ and activate $\mathrm{Ca}^{2+}$-dependent $\mathrm{Cl}^{-}$ channels. Forskolin (cAMP)-dependent $\mathrm{Cl}^{-}$secretion was observed in non-CF small airways (21). Interestingly, addition of the CFTR inhibitor DPC to non-CF bronchioles decreased the residual $\mathrm{I}_{\mathrm{sc}}$ in the presence of amiloride, suggesting that CFTRdependent $\mathrm{Cl}^{-}$secretion is revealed when $\mathrm{Na}^{+}$absorption is inhibited. Forskolin failed to increase $\mathrm{I}_{\mathrm{sc}}$ significantly in the presence of amiloride in $\mathrm{CF}$ bronchiolar cultures. In addition, the residual $\mathrm{I}_{\mathrm{sc}}$ after addition of amiloride was significantly lower in $\mathrm{CF}$ than in non-CF preparations, which likely reflects failure 
to initiate $\mathrm{Cl}^{-}$secretion. The absence of cAMP-regulated $\mathrm{Cl}^{-}$ secretion was expected because defective function of CFTR $\mathrm{Cl}^{-}$ channel activity is the hallmark of $\mathrm{CF}$, and this defect has been reported in all epithelia in organs clinically affected by the disease, including the large airways.

In addition to the defect in cAMP-regulated $\mathrm{Cl}^{-}$secretion, we observed differences in ATP-activated $\mathrm{Cl}^{-}$secretion in $\mathrm{CF}$ and non-CF bronchioles. In vivo and in vitro studies have demonstrated that the application of the purinergic agonists ATP or uridine 5'triphosphate (UTP) to the apical surface of large airways stimulated $\mathrm{Cl}^{-}$secretion to a similar or higher extent in $\mathrm{CF}$ compared with non-CF airways (43-45). Several hypotheses have been raised to explain this observation. For instance, CFTR might attenuate $\mathrm{Ca}^{2+}$-dependent $\mathrm{Cl}^{-}$channel responses in normal tissues by reducing the driving force for $\mathrm{Cl}^{-}$exit across the luminal membrane of airway epithelial cells (46). Recently, Ribeiro and coworkers provided evidence that, in CF bronchial epithelium, the mechanism for the larger intracellular $\mathrm{Ca}^{2+}$ signals elicited by activation of the apical purinergic receptors $\left(\mathrm{P}_{2} \mathrm{Y}_{2}\right)$ is an expansion of the apical endoplasmic reticulum $\mathrm{Ca}^{2+}$ stores triggered by chronic luminal airway infection or inflammation (47). The cause of the decreased response to ATP in our CF bronchiolar preparations compared with their non-CF counterparts remains to be determined. It has been suggested that the increased purinergic agonist-mediated $\mathrm{Cl}^{-}$secretion may counterbalance the lack of inducible cAMP-dependent $\mathrm{Cl}^{-}$secretion in $\mathrm{CF}$ large airways $(44,45)$. This compensatory mechanism, if confirmed, may be limited in small airways, which could aggravate the defect in transepithelial $\mathrm{Cl}^{-}$secretion and contribute to the severity and precocity of the $\mathrm{CF}$ disease in small airways.

To relate the measurements of transepithelial ion transport to fluid transport, we measured the ASL height in primary cultures of non-CF and CF bronchiolar epithelial cells using confocal microscopy. In bronchiolar preparations, the decrease in ASL height after addition of an excess volume of fluid was faster in $\mathrm{CF}$ compared with non-CF preparations and the resulting ASL height was significantly lower in CF preparations. These data indicate that $\mathrm{CF}$ bronchioles absorb fluid more rapidly than non$\mathrm{CF}$ bronchioles, and $\mathrm{CF}$ bronchioles cannot regulate ASL to maintain sufficient volume for efficient mucus transport. In this respect, bronchioles are similar to bronchi: using confocal microscopy, Tarran and coworkers measured the ASL height in primary cultures of human non-CF and CF bronchial epithelial cells (42). They found that $24 \mathrm{~h}$ after addition of an excess volume of fluid on the cultures, the ASL height was approximately $7 \mu \mathrm{m}$ in normal cultures and $3 \mu \mathrm{m}$ in CF cultures (42). We found similar results in bronchiolar preparations. In CF bronchi, the increased absorption of ASL results from both increased (unregulated) $\mathrm{Na}^{+}$absorption and defective CFTR-dependent $\mathrm{Cl}^{-}$secretion $(6,42)$. In CF bronchioles, our results suggest that the increased absorption of ASL results from unregulated $\mathrm{Na}^{+} \mathrm{ab}-$ sorption in the face of decreased cAMP-activated $\mathrm{Cl}^{-}$secretion. Their results strengthen the current theory on the pathogenesis of CF lung disease (i.e., ASL depletion leading to impaired mucus clearance, which in turn favors recurrent bacterial infections and lung function deterioration), which until now was based only on knowledge of ion and fluid transport in large airways.

Because a key difference between non-CF and CF small airways was the defect in cAMP-activated $\mathrm{Cl}^{-}$secretion, we assessed the functional capacity of cAMP-activated $\mathrm{Cl}^{-}$and fluid secretions in non-CF large and small airways. To minimize any variability due to differences in genetic background, age, smoking status, and treatments, we obtained similarly processed primary cultures of bronchial and bronchiolar epithelial cells from the same patients. The forskolin-induced increase in $\mathrm{I}_{\mathrm{sc}}$ was significantly higher in bronchiolar than in bronchial cultures, sug- gesting that the $\mathrm{Cl}^{-}$secretion in response to cAMP was higher in bronchioles. This difference in forskolin-dependent $\Delta \mathrm{I}_{\mathrm{sc}}$ in the two airway regions was paralleled by differences in fluid secretion. Confocal microscopy experiments revealed that bronchial and bronchiolar cultures displayed increased ASL height in response to forskolin, reflecting fluid secretion. This increase was significantly higher in bronchiolar compared with bronchial cultures. Physiologically, one could argue that a greater $\mathrm{Cl}^{-}$driven fluid secretion may compensate the lack of fluid-secreting submucosal glands in small airways (48). The defective response to forskolin in CF may have more severe consequences in terms of fluid secretion in bronchioles compared with bronchi.

\section{CONCLUSIONS}

The data provide clues to differences in the ion and fluid transport properties of large and small airways and add to knowledge about physiologic similarities and differences between these two airway regions. We found that the bioelectric properties of $\mathrm{CF}$ bronchiolar epithelial cultures measured in Ussing chambers differed from their non-CF counterparts in terms of $\mathrm{Cl}^{-}$secretion but not of the absolute rate of amiloride-sensitive $\mathrm{Na}^{+}$absorption. The data from ASL volume measurements reveal low ASL volume in $\mathrm{CF}$, but not in normal bronchiolar cultures after a volume challenge, likely reflecting unregulated (persistent) $\mathrm{Na}^{+}$ absorption and defective CFTR-dependent $\mathrm{Cl}^{-}$secretion. These observations may have several implications for the understanding of distal airways physiology: (1) the epithelia of large and small normal airways share many similarities in terms of ion and fluid transport but exhibit some differences with respect to the magnitude of CFTR-regulated $\mathrm{Cl}^{-}$and fluid secretion, (2) CFTR defects result in ASL depletion in bronchiolar and bronchial airway regions, and (3) CF bronchiolar defects reflect the absence of CFTR-mediated $\mathrm{Cl}^{-}$secretion likely combined with unregulated (persistent) $\mathrm{Na}^{+}$absorption under these experimental conditions.

Conflict of Interest Statement: None of the authors has a financial relationship with a commercial entity that has an interest in the subject of this manuscript.

Acknowledgment: The authors thank Maryse Picher (University of North Carolina, Chapel Hill, NC) for critical review of the manuscript.

\section{References}

1. Boucher RC. Human airway ion transport. Am J Respir Crit Care Med 1994;150:271-281; 581-593.

2. Schwiebert EM, Benos DJ, Egan ME, Stutts MJ, Guggino WB. CFTR is a conductance regulator as well as a chloride channel. Physiol Rev 1999;79:S145-S166.

3. Kunzelmann K. The CFTR and its function in epithelial transport. Rev Physiol Biochem Pharmacol 1999;137:1-70.

4. Stutts MJ, Rossier BC, Boucher RC. Cystic fibrosis transmembrane conductance regulator inverts protein kinase A-mediated regulation of epithelial sodium channel single channel kinetics. J Biol Chem 1997; 272:14037-14040.

5. Boucher RC. New concepts of the pathogenesis of cystic fibrosis lung disease. Eur J Respir 2004;23:146-158.

6. Boucher RC. An overview of the pathogenesis of cystic fibrosis lung disease. Adv Drug Deliv Rev 2002;54:1359-1371.

7. Matsui H, Randell SH, Peretti SW, Davis W, Boucher RC. Coordinated clearance of periciliary liquid and mucus from airway surfaces. J Clin Invest 1998:102:1125-1131.

8. Boers JE, Ambergen AW, Thunnissen FBJM. Number and proliferation of Clara cells in normal human airway epithelium. Am J Respir Crit Care Med 1999;159:1585-1591.

9. Boers JE, Ambergen AW, Thunnissen FBJM. Number and proliferation of basal and parabasal cells in normal human airway epithelium. Am J Respir Crit Care Med 1998;157:2000-2006.

10. Wentworth P, Gough J, Wentworth JE. Pulmonary changes and cor pulmonale in mucoviscidosis. Thorax 1968;23:582-589. 
11. Martinez TM, Llapur CJ, Williams TH, Coates C, Gunderman R, Cohen MD, Howenstine MS, Saba O, Coxson HO, Tepper RS. High-resolution computed tomography imaging of airway disease in infants with cystic fibrosis. Am J Respir Crit Care Med 2005;172:1133-1138.

12. Wood RE, Boat TF, Doershuk CF. Cystic fibrosis. Am Rev Respir Dis 1976;113:833-878.

13. Long FR, Roger S, Williams BS, Castile RG. Structural airway abnormalities in infants and young children with cystic fibrosis. J Pediatr 2004;144: 154-161.

14. Sobonya RE, Taussig LM. Quantitative aspects of lung pathology in cystic fibrosis. Am Rev Respir Dis 1986;134:290-295.

15. Hamutcu R, Rowland JM, Horn MV, Kaminsky C, MacLaughlin EF, Starnes VA, Woo MS. Clinical findings and lung pathology in children with cystic fibrosis. Am J Respir Crit Care Med 2002;165:1172-1175.

16. Sheppard MN. The pathology of cystic fibrosis. In: Hodson ME, Geddes DM, editors. Cystic fibrosis. London: Chapman and Hall; 1995. pp. 131-149.

17. Khan TZ, Wagener JS, Bost T, Martinez J, Accurso FJ, Riches DW. Early pulmonary inflammation in infants with cystic fibrosis. Am J Respir Crit Care Med 1995;151:1075-1082.

18. Noah TL, Murphy PC, Alink JJ, Leigh MW, Hull WM, Stahlman MT, Whitsett JA. Bronchoalveolar lavage fluid surfactant protein-A and surfactant protein-D are inversely related to inflammation in early cystic fibrosis. Am J Respir Crit Care Med 2003;168:685-691.

19. Mellins R. The site of airway obstruction in cystic fibrosis. Pediatrics 1969:44:315-318.

20. Ranganathan SC, Stocks J, Dezateux C, Bush A, Wade A, Carr S, Castle R, Dinwiddie R, Hoo AF, Lum S, et al. The evolution of airway function in early childhood following clinical diagnosis of cystic fibrosis. Am J Respir Crit Care Med 2004;169:928-933.

21. Blouquit S, Morel H, Hinnrasky J, Puchelle E, Chinet TC. Characterization of ion and fluid transport in human bronchioles. Am J Respir Cell Mol Biol 2002;27:503-510.

22. Blouquit S, Boucher RC. Regulation of airway surface liquid volume by human non-CF and CF distal airway epithelia [abstract]. Pediatr Pulmonol 2004(Suppl 28);217.

23. Blouquit $\mathrm{S}$, Naline $\mathrm{E}$, Chinet TC. Ion transport in human non-CF and CF distal airway epithelium [abstract]. J Cyst Fibros 2002;S50-S51.

24. Lechner JF, LaVeck MA. A serum-free method for culturing normal human bronchial epithelial cells at clonal density. J Tiss Cult Methods 1985;9:43-48.

25. Tarran R, Grubb BR, Parsons D, Picher M, Hirsh AJ, Davis CW, Boucher RC. The CF salt controversy: in vivo observations and therapeutic approaches. Mol Cell 2001;8:149-158.

26. Yankaskas JR, Cotton CU, Knowles MR, Gatzy JT, Boucher RC. Culture of human nasal epithelial cells on collagen matrix supports: a comparison of bioelectric properties of normal and cystic fibrosis epithelia. Am Rev Respir Dis 1985;132:1281-1287.

27. Knowles MR, Stutts MJ, Yankaskas JR, Gatzy JT, Boucher RC. Abnormal respiratory epithelial ion transport in cystic fibrosis. Clin Chest Med 1986;7:285-297.

28. Randell SH, Walstad L, Schwab UE, Grubb BR, Yankaskas JR. Isolation and culture of airway epithelial cells from chronically infected human lungs. In Vitro Cell Dev Biol Anim 2001;37:480-489.

29. Mercer RR, Russel ML, Crapo JD. Radon dosimetry based on the depth distribution of nuclei in human and rat lungs. Health Phys 1991;61:117130 .

30. Willumsen NJ, Boucher RC. Shunt resistance and ion permeabilities in normal and cystic fibrosis airway epithelia. Am J Physiol 1989;256: C1054-C1063.

31. Chinet TC, Fullton JM, Yankaskas JR, Boucher RC, Stutts MJ. Sodiumpermeable channels in the apical membrane of human nasal epithelial cells. Am J Physiol 1993;265:C1050-C1060.

32. Willumsen NJ, Boucher RC. Intracellular $\mathrm{pH}$ and its relationship to regulation of ion transport in normal and cystic fibrosis human nasal epithelia. J Physiol 1992;455:247-269.

33. Mall M, Bleich M, Greger R, Schreiber R, Kunzelmann K. The amilorideinhibitable $\mathrm{Na}+$ conductance is reduced by the cystic fibrosis transmembrane conductance regulator in normal but not in cystic fibrosis airways. J Clin Invest 1998;102:12-21.

34. Knowles M, Murray G, Shallal J, Askin F, Ranga V, Gatzy J, Boucher R. Bioelectric properties and ion flow across excised human bronchi. J Appl Physiol 1984;56:868-877.

35. Devor DC, Bridges RJ, Pilewski JM. Pharmacological modulation of ion transport across wild-type and 8 F508 CFTR-expressing human bronchial epithelia. Am J Physiol 2000;279:C461-C479.

36. Steel DM, Graham A, Geddes DM, Alton EWFW. Characterization and comparison of ion transport across sheep and human airway epithelium. Epithelial Cell Biol 1994;3:24-31.

37. Al-Bazzaz FJ, Gailey C. Ion transport by sheep small airways in a miniature chamber. Am J Physiol 2001;281:L1028-L1034.

38. Pitkanen OM, Smith D, O'Brodovich H, Otulakowski G. Expression of $\alpha-, \beta-$, and $\gamma-\mathrm{hENaC}$ mRNA in the human nasal, bronchial, and distal lung epithelium. Am J Respir Crit Care Med 2001;163:273-276.

39. Gaillard D, Hinnrasky J, Coscoy S, Hofmann P, Matthay MA, Puchelle E, Barbry P. Early expression of $\beta$ - and $\gamma$-subunits of epithelial sodium channel during human airway development. Am J Physiol 2000;278: L177-L184.

40. Mall M, Bleich M, Kuehr J, Brandis M, Greger R, Kunzelmann K. CFTRmediated inhibition of epithelial $\mathrm{Na}^{+}$conductance in human colon is defective in cystic fibrosis. Am J Physiol 1999;277:G709-G716.

41. Reddy M, Quinton PM. Functional interaction of CFTR and ENaC in sweat glands. Eur J Physiol 2003;445:499-503.

42. Tarran R, Button B, Picher M, Paradiso AM, Ribeiro CM, Lazarowski ER, Zhang L, Collins PL, Pickels RJ, Fredberg JJ, et al. Normal and cystic fibrosis airway surface liquid homeostasis: the effects of phasic shear stress and viral infections. J Biol Chem 2005;280:35751-35759.

43. Boucher RC, Cheng EH, Paradiso AM, Stutts MJ, Knowles MR, Earp HS. Chloride secretory response of cystic fibrosis human airway epithelia: preservation of calcium but not protein kinase C- and A-dependent mechanisms. J Clin Invest 1989;84:1424-1431.

44. Clarke LL, Boucher RC. Chloride secretory response to extracellular ATP in human normal and CF nasal epithelia. Am J Physiol 1992;263: 348-356.

45. Knowles MR, Clarke LL, Boucher RC. Activation by extracellular nucleotides of chloride secretion in the airway epithelia of patients with cystic fibrosis. N Engl J Med 1991;325:533-538.

46. Mall M, Gonska T, Thomas J, Schreiber R, Seydewitz HH, Kuehr J, Brandis M, Kunzelmann K. Modulation of $\mathrm{Ca}^{2+}$-activated $\mathrm{Cl}^{-}$secretion by basolateral $\mathrm{K}^{+}$channels in human normal and cystic fibrosis airway epithelia. Pediatr Res 2003;53:608-618.

47. Ribeiro CMP, Paradiso AM, Carew MA, Shears SB, Boucher RC. Cystic fibrosis airway epithelial $\mathrm{Ca}^{2+}{ }_{\mathrm{i}}$ signalling: the mechanism for the larger agonist-mediated $\mathrm{Ca}^{2+}{ }_{\mathrm{i}}$ signals in human cystic fibrosis airway epithelia. J Biol Chem 2005;280:10202-10209.

48. Ballard ST, Inglis SK. Liquid secretion properties of airway submucosal glands. J Physiol 2004;556:1-10. 